\title{
LEY APLICABLE A LOS SMART CONTRACTS Y LEX CRYTOGRAPHIA
}

\section{APPLICABLE LAW TO SMART CONTRACTS AND LEX CRYPTOGRAPHIA}

\author{
Ana Mercedes López Rodríguez \\ Profesora titular de Derecho Internacional Privado \\ Universidad Loyola Andalucía
}

Recibido: 09.12.2020 / Aceptado: 21.12.2020

DOI: https://doi.org/10.20318/cdt.2021.5966

\begin{abstract}
Resumen: La irrupción de los smart contracts o contratos inteligentes basados en la cadena de bloques plantea importantes desafíos para el Derecho contractual y el Derecho internacional privado. Estos contratos tienen, además, la capacidad de operar, en gran medida, al margen del ordenamiento jurídico y, con ello, de poner en jaque al tradicional monopolio legislativo del Estado. Algunos ya vaticinan que los algoritmos terminarán por desplazar a la Ley y a jueces y tribunales, una vez se consolide lo que se denomina la Lex Cryptographia. Ante esta situación, el presente trabajo aborda tres cuestiones principales: Primero, analiza la ley aplicable a los smart contracts bajo el régimen del Reglamento Roma I. Segundo, estudia el fenómeno de la Lex Cryptographia y su interacción con el ordenamiento jurídico estatal. Finalmente, examina el papel del Derecho internacional privado para garantizar la seguridad jurídica en la contratación inteligente, así como el adecuado equilibrio entre regulación e innovación tecnológica.

Palabras clave: blockchain, smart contracts, Lex Cryptographia, ley aplicable, Derecho internacional privado, competencia regulatoria.
\end{abstract}

Abstract: Blockchain-based smart contracts pose significant challenges for Contract Law and Private International Law. At the same time, smart contracts using blockchain technology can largely operate outside the legal system and thereby, challenge the traditional legislative monopoly of the State. Some even predict that algorithms will eventually replace the law and the judicial system, once the socalled Lex Cryptographia is consolidated. Against this background, the present article addresses three main issues: First, it deals with the applicable law to smart contracts under the Rome I Regulation. Second, it studies the phenomenon of the Lex Cryptographia and its interaction with the state legal system. Finally, it analyses the ability of Private International Law to respond to some of the main challenges that arise in relation to smart contracts, namely, the need to provide legal certainty and a right balance between regulation and technological development.

Keywords: blockchain, smart contracts, Lex Cryptographia, applicable law, Private International Law, regulatory competition.

Sumario: I. Introducción. Los contratos inteligentes. II. La ley aplicable a los smart contracts bajo el Reglamento Roma I. III. La Lex Cryptographia. IV. Equilibrio entre legislación y autorregulación. El papel del Derecho internacional privado. 1. Seguridad jurídica. Autonomía de las partes y lex fori. 2. Competencia regulatoria y desarrollo tecnológico. A) Competencia regulatoria. B) Equilibrio entre regulación y desarrollo tecnológico. Interacción con la Lex Cryptographia. V. Conclusiones. 


\section{Introducción. Los contratos inteligentes}

1. El término smart contracts o contratos inteligentes fue acuñado por el informático y jurista Nick SzABo en 1994 como aquellos acuerdos contractuales donde la verificación, aplicación y ejecución de los términos del contrato está automatizada, ${ }^{1}$ por ejemplo, una máquina expendedora de bebidas. En los últimos años el término ha empezado a utilizarse en referencia a programas informáticos que eliminan la discreción humana en la ejecución del contrato. Con ello se garantiza el cumplimiento de los términos contractuales sin tener que recurrir a jueces y tribunales, ${ }^{2}$ puesto que el programa tiene el control sobre aquellos objetos físicos o digitales necesarios para realizar la ejecución. Ejemplos de smart contracts son un programa instalado en un vehículo que evita su puesta en marcha si los términos del alquiler no se cumplen, o un software bancario que transfiere automáticamente dinero, si se cumplen ciertas condiciones.

2. La aparición de la tecnología blockchain ha supuesto una vuelta de tuerca para la contratación inteligente, puesto que los términos del contrato y las condiciones relacionadas con su ejecución pueden ser programadas en la cadena de bloques y, con ello, garantizar la confianza que supone su inmutabilidad y neutralidad. De esta forma, se obtiene un programa que siempre va a actuar de la misma forma, sin requerir de la buena voluntad de la otra parte o de un tercero. ${ }^{3}$

3. En la blockchain las transacciones se llevan a cabo peer to peer o de usuario a usuario, están encadenadas unas con otras y no pueden separarse, por lo que el acceso a una determinada transacción permite conocer todo su historial previo. Efectivamente, cada operación se registra irreversiblemente en un bloque de datos que almacena varias operaciones y cuyo contenido se encripta a través de un algoritmo llamado "hash," estando la clave de encriptado de cada transacción basada en la transacción anterior. La clave es crucial para desencriptar la información y poderla leer de nuevo. Por ello, si se ha manipulado la transacción anterior, la transacción actual no será legible. ${ }^{4}$

Los bloques se distribuyen entre los diferentes nodos, de forma que cada transacción se registra uniformemente entre los participantes, una vez ratificada la validez de la operación en base a transacciones anteriores. Puesto que la información contenida en una cadena de bloques no puede ser suprimida o alterada sin el consenso de la red, se ha afirmado que la cadena de bloques es "simultáneamente resistente, transparente e inviolable." 5

Una transacción se inicia en la blockchain cuando el remitente introduce una clave digital única que permanece en secreto para él ("clave privada") y la clave públicamente conocida del destinatario ("clave pública") a una cadena de firmas digitales en Internet. ${ }^{6}$ Todas las transacciones son públicas, pero se consideran anónimas porque nada relaciona a individuos u organizaciones con las cuentas identificadas en las transacciones.

4. La plataforma pionera en ofrecer soluciones para desarrollar smart contracts fue Ethereum $^{7}$ en 2014, utilizando Solidity como lenguaje de programación, aunque ya han surgido muchas otras platafor-

\footnotetext{
${ }^{1}$ N. SzABO, Smart Contracts, 1994, disponible en: https:/www.fon.hum.uva.n1/rob/Courses/InformationInSpeech/CDROM/ Literature/LOTwinterschool2006/szabo.best.vwh.net/smart.contracts.html (consultado el 7 de diciembre de 2020).

2 M. RASKIn, "The Law and Legality of Smart Contracts", Georgetown Law Technology Review, vol. 1, 2017, pp. 305-341.

${ }^{3}$ C. Argelich Comelles, "Smart contracts o Code is Law: soluciones legales para la robotización contractual", Indret, vol. 2 , 2020, pp. 1-41, p. 14. DOI: 10.31009/InDret.2020.i2.01; A. LegerÉn-Molina, Revista de Derecho Civil, vol. V, núm. 2, abril-junio 2018, pp. 193-241, p. 196.

${ }^{4}$ A. Rangone, Managing Corporate Innovation. Determinants, Critical Issues and Success Factors, Cham, Springer Nature, 2019, p. 78.

${ }^{5}$ B. Carron y V. Botteron, "How smart can a contract be?" en D. Kraus, T. Obrist y O. Hari (eds.), Blockchains, Smart Contracts, Decentralised Autonomous Organisations and the Law, Cheltenham, Edward Elgar Publishing, 2019, pp. 101, 106.

${ }^{6}$ S. Naкамото, "Bitcoin: A Peer-to-Peer Electronic Cash System," Bitcoin Project, http://bitcoin.org/bitcoin.pdf, p. 2 (consultado el 7 de diciembre de 2020).

${ }^{7}$ https://ethereum.org (consultado el 7 de diciembre de 2020).
} 
mas basadas en la tecnología de la cadena de bloques, como, por ejemplo, Hyperledger ${ }^{8}$ Counterparty, ${ }^{9}$ RSK $^{10}$ o Corda. ${ }^{11}$

5. Entre las ventajas destacables de la utilización de contratos inteligentes se suelen mencionar: ${ }^{12}$ (i) autonomía: se puede prescindir de abogados, notarios o cualquier otro intermediario para firmar un contrato o acuerdo; (ii) confianza: la encriptación y la validación descentralizada y mediante consenso hace casi imposible que los documentos se puedan perder o cambiar; (iii) seguridad: el encriptado y la información validada en varios bloques a la vez, limita las posibilidades de hackeos; (iv) rapidez: al ser acuerdos autoejecutables no se necesita la acción de la otra parte o la intervención de terceros, por lo que hay inmediatez; (v) ahorro: al ser autoejecutables, se elimina la necesidad de tener que pleitear para hacer cumplir lo que está recogido en el contrato y (vi) exactitud: el lenguaje computacional es extremadamente preciso, lo que permite asegurar que se va a ejecutar exactamente lo que dice el contrato, eliminando posibles errores ligados a la intervención de personas para llevar a cabo las acciones que conllevan.

6. No obstante, estas herramientas también llevan aparejadas algunos inconvenientes. Por ejemplo, su conformidad con la normativa sobre protección de datos no está del todo clara. El acceso a los datos personales por parte de los distintos actores (propietarios de la red, desarrolladores de la tecnología, nodos participantes en la red o los propios interesados) y su situación en un plano de igualdad en la red, complica la determinación de la condición de responsable y encargado de tratamiento entre los mismos, tal como exige el Reglamento general de protección de datos (RGPD). ${ }^{13}$ De la misma manera, el ejercicio de los derechos de supresión y rectificación no está garantizado, ya que los smart contracts operan en una red inmutable. La inmutabilidad imposibilita, a su vez, la modificación del acuerdo ante circunstancias sobrevenidas en la relación contractual o su adaptación a los cambios normativos. Tampoco se trata de herramientas infalibles. A pesar de que los contratos inteligentes se formulan con precisión, no quedan inmunes frente a errores de programación (bugs) o posibles hackeos, tal como ocurrió con la Organización Autónoma Descentralizada (DAO) de 2016. ${ }^{14}$

7. Los smart contracts existen y se ejecutan dentro de la red, pero se relacionan con su entorno a través de herramientas informáticas que permiten actualizar el estado del contrato con la incorporación de información externa. Son los denominados "oráculos" (oracles en inglés) ${ }^{15}$ instrumentos indispensables para que un smart contract pueda interactuar con el mundo real, por ejemplo, obtener la cotización de una acción o divisa o si un paquete ha sido enviado por la empresa de transportes. Dicho esto, no todos los smart contracts existen exclusivamente en la cadena de bloques. Podemos encontrar contratos inteligentes puros, que solo operan en la red, pero también "traducciones" de contratos tradicionales a contratos inteligentes, así como contratos inteligentes combinados, en los que parte del articulado existe fuera de la red y otra parte opera como código informático. Estos smart contracts híbridos incluyen los

\footnotetext{
${ }^{8} \mathrm{https}: / /$ www.hyperledger.org (consultado el 7 de diciembre de 2020).

${ }^{9} \mathrm{https}: / /$ counterparty.io (consultado el 7 de diciembre de 2020).

${ }^{10} \mathrm{https}: / /$ www.rsk.co (consultado el 7 de diciembre de 2020).

${ }^{11} \mathrm{https}: / /$ www.corda.net (consultado el 7 de diciembre de 2020).

12 A. Ortega Giménez, "Smart Contracts" y Derecho Internacional Privado, Navarra, Thomson Reuters Aranzadi, 2019, pp. 30-31. A. E. VILALTA NicueSA, Smart legal contracts y blockchain: la contratación inteligente a través de la tecnología blockchain, Madrid, Wolters Kluwer España, 2019, Cap. 4; A. Legerén-Molina, Revista de Derecho Civil, vol. V, núm. 2 , abril-junio 2018, pp. 193-241, p. 205 ss.; C. Argelich Comelles, "Smart contracts o Code is Law: soluciones legales para la robotización contractual”, Indret, vol. 2, 2020, pp. 1-41. DOI: 10.31009/InDret.2020.i2.01.

${ }^{13}$ Reglamento (UE) 2016/679 del Parlamento Europeo y del Consejo, de 27 de abril de 2016, relativo a la protección de las personas físicas en lo que respecta al tratamiento de datos personales y a la libre circulación de estos datos y por el que se deroga la Directiva 95/46/CE (Reglamento general de protección de datos), DO L 119 de 4.5.2016, p. 1/88.

${ }^{14}$ N. Atzei, M. Bartoletti, T. Cimoli, "A survey of attacks on Ethereum smart contracts", Proceedings of the 6th International Conference on Principles of Security and Trust, vol. 10204, 2017, pp. 1-23, https://eprint.iacr.org/2016/1007.pdf (consultado el 7 de diciembre de 2020).

${ }^{15}$ R. Unsworth, "Smart Contract This! An Assessment of the Contractual Landscape and the Herculean Challenges it Currently Presents for "Self-executing" Contracts" en M. Corrales, M. Fenwick y H. HaAPIO (eds.), Legal Tech, Smart Contracts and Blockchain, Singapur, Springer, 2019, pp. 17-61, p. 21.
} 
denominados contratos ricardianos (Ricardian contracts), término empleado por primera vez por el criptógrafo financiero IAN GRIGG a mediados de los noventa del pasado siglo, en honor al economista inglés DAVID RicARDO. ${ }^{16}$ Se trata de contratos digitales que definen los términos y condiciones de una interacción entre dos o más partes, firmados y verificados criptográficamente. En los contratos ricardianos las cláusulas de lenguaje natural van "atornilladas" a un contrato inteligente. Es decir, la información de un texto legal se convierte a un formato que puede ser ejecutado por una computadora. En consecuencia, son legibles tanto para los humanos como para las máquinas. ${ }^{17}$

8. Los contratos inteligentes suponen un reto para el Derecho en muchos sentidos. El primero de ellos es determinar si estamos o no ante verdaderos contratos, es decir, si la teoría general del Derecho de contratos es aplicable o, por el contrario, encontramos elementos en estos instrumentos tecnológicos que hacen descartar esa opción. En el primer caso estaremos hablando smart legal contracts, que sirven para el intercambio de prestaciones mientras que, en el segundo, estaremos ante meros smart code contracts, que son jurídicamente irrelevantes por tratarse de una mera secuencia de código informático. ${ }^{18}$

9. De otro lado, la descentralización, anonimidad/opacidad, inmutabilidad, interconectividad y automatización características de los smart contracts generan complejas cuestiones legales para el Derecho Internacional Privado. Por ejemplo, la descentralización y la anonimidad dificultan la determinación de la identidad de los operadores, su ubicación y de las acciones que han llevado a cabo, lo que puede suponer un obstáculo a la hora de asignar de responsabilidades o fijar el juez competente en caso de conflicto. Ello complica, a su vez, el desempeño de funciones regulatorias básicas, tales como establecer la ley aplicable a la controversia, la responsabilidad derivada de los hechos y el cumplimiento de las decisiones adoptadas. ${ }^{19}$

10. El presente artículo analiza la capacidad del Derecho internacional privado para dar respuesta a los principales retos que origina la contratación inteligente. Con este fin, el apartado II presenta el marco normativo aplicable dentro del régimen del Reglamento Roma I. Por su parte, el apartado III estudia el fenómeno de la denominada Lex Cryptographia. Posteriormente, el apartado IV aborda la interacción de la Lex Cryptographia con el ordenamiento jurídico estatal, destacando la capacidad del Derecho internacional privado para garantizar la seguridad jurídica y un equilibrio adecuado entre regulación e innovación tecnológica. Finalmente, el apartado V concluye.

A modo de aclaración, el artículo se centra especialmente en los aspectos relacionados con la ley aplicable al contrato, aunque hace alguna pequeña referencia a cuestiones concretas de competencia judicial internacional y eficacia extraterritorial de decisiones. Por razones de espacio, no se abordan otros aspectos igual de relevantes para la contratación inteligente, tales como la ley aplicable a las obligaciones extracontractuales o los derechos reales (por ejemplo, el régimen aplicable a los criptoactivos). ${ }^{20}$

\section{La ley aplicable a los smart contracts bajo el Reglamento Roma I}

11. Una de las técnicas históricamente vinculadas al Derecho internacional privado es la norma de conflicto, que permite localizar una determinada situación o relación jurídica en un concreto

\footnotetext{
${ }^{16}$ J. LAMPIČ, "Ricardian contracts: A smarter way to do smart contracts?", Schoenherr Blog (enero 2019), https://www. schoenherr.eu/publications/publication-detail/ricardian-contracts-a-smarter-way-to-do-smart-contracts (consultado el 7 de diciembre de 2020).

${ }^{17}$ T. D. Barton, H. HaApio, S. Passera y J.G. Hazard, “Successful Contracts: Integrating Design and Technology”, en M. Corrales, M. Fenwick y H. HaApio (eds.), Legal Tech, Smart Contracts and Blockchain, Singapur, Springer, 2019, pp. 63-91, p. 82 ss.

${ }^{18}$ J. Stark, "How Close Are Smart Contracts to Impacting Real-World Law?", CoinDesk (11 de abril de 2016), https:// www.coindesk.com/blockchain-smarts-contracts-real-world-law (consultado el 7 de diciembre de 2020).

19 "La regulación de Blockchain y los Smart contracts va a requerir la armonización de conceptos, principios, regulación e interpretaciones", Especial Directivos, núm. 1765, 1 de noviembre de 2019, pp. 38-42, p. 39.

${ }^{20}$ Vid. en este sentido, R. Ruiz Rodríguez, "Las criptodivisas como medio de pago y el Derecho internacional privado", Cuadernos de Derecho Transnacional, vol. 12, n², octubre 2020, pp. 740-757, p. 755.
} 
ordenamiento jurídico nacional, otorgando una respuesta indirecta a la cuestión suscitada. ${ }^{21}$ En materia contractual, con la salvedad de la Convención de Viena de 1980 sobre Compraventa internacional de Mercaderías ${ }^{22}$ y los convenios internacionales de Derecho uniforme relativos al transporte, ${ }^{23}$ no existen apenas normas sustantivas con amplio respaldo internacional que aporten directamente una solución a las cuestiones que se originen, por lo que las normas de conflicto deberán seleccionar cuál de los ordenamientos jurídicos vinculados con el contrato es el que se encuentra mejor situado para su regulación.

12. Dentro de la Unión Europea y con la salvedad de Dinamarca, ${ }^{24}$ el Reglamento de Roma $\mathrm{I}^{25}$ determina el Derecho aplicable si el contrato inteligente en cuestión contiene verdaderas obligaciones contractuales (art.1.1), esto es, si estamos ante un smart legal contract.

Teniendo en cuenta las diferentes definiciones de contrato y los elementos esenciales que se suelen exigir por los distintos ordenamientos para otorgarles fuerza vinculante, descubrimos de forma inmediata que los contratos inteligentes plantean una serie de problemas con relación a la definición de obligación contractual. En el common law, por ejemplo, lo que diferencia a un contrato de meros acuerdos sociales o morales es la posibilidad de acudir a los tribunales en caso de incumplimiento. Es decir, un contrato es un acuerdo cuya infracción da lugar a acciones legales. ${ }^{26}$ Sin embargo, en un smart contract la ejecución no está asegurada mediante los mecanismos coercitivos del Estado, sino por los términos y mecanismos establecidos en el programa informático que le da origen. ${ }^{27}$ Por otra parte, los contratos inteligentes no crean per se obligaciones en sentido jurídico. La noción de obligación, que se origina en el Derecho romano y es clave en el Derecho de contratos del sistema continental, es ajena a los smart contracts. Según la clásica definición de Justiniano, "la obligación es un vínculo jurídico por el que somos constreñidos con la necesidad de pagar alguna cosa según las leyes de nuestra ciudad." 28 Es decir, es el vínculo establecido entre dos personas (o grupos de personas), por el que una de ellas puede exigir de la otra la entrega de una cosa o el cumplimiento de un servicio o de una abstención. ${ }^{29}$ Un elemento clave de la obligación es, por tanto, su orientación hacia el futuro. Aunque los distintos ordenamientos suelen dar cobertura a contratos que se ejecutan instantáneamente en el momento de su celebración (v.gr. executed contracts en el Derecho angloamericano), según la doctrina, es más correcto afirmar que la principal consecuencia de la celebración de un smart contract no es la de dar origen a obligaciones, sino la autolimitación de ciertos derechos por medios técnicos. ${ }^{30}$

Estos obstáculos de carácter dogmático son, sin embargo, fácilmente salvables en el contexto del Reglamento Roma I, puesto que la noción de obligación contractual es un concepto autónomo, extrapolable del art. 5(1) del Reglamento Bruselas I, esto es, se define como "un vínculo jurídico volun-

${ }^{21}$ A. L. Calvo Caravaca y J. Carrascosa González (directores), Derecho internacional privado, Vol. I, $18^{\mathrm{a}}$ ed., Granada, Comares, 2018, p. 193; G. Palao Moreno, J. L. Iglesias Buhigues y C. Esplugues Mota, Derecho internacional privado, $14^{\text {a }}$ ed., Valencia, Tirant lo Blanch, 2020, p. 227.

${ }^{22}$ Convención de las Naciones Unidas sobre los contratos de compraventa internacional de mercaderías (Convención de Viena) de 11 de abril de 1980 (BOE núm. 26, de 30 de enero de 1991).

${ }^{23}$ Vid. el listado completo en A. L. Calvo Caravaca y J. Carrascosa González (directores), Derecho internacional privado, Vol. II, $18^{\mathrm{a}}$ ed., Granada, Comares, 2018, pp. 1060 ss.

${ }^{24}$ Donde se aplica el Convenio de Roma de 1980 sobre ley aplicable a las obligaciones contractuales, Convenio 80/934/ CEE sobre la ley aplicable a las obligaciones contractuales abierto a la firma en Roma el 19 de junio de 1980, DO L 266 de 9 de octubre de 1980, p. 1.

${ }^{25}$ Reglamento (CE) n ${ }^{0}$ 593/2008 del Parlamento Europeo y del Consejo, de 17 de junio de 2008, sobre la ley aplicable a las obligaciones contractuales (Roma I), DOUE L 177 de 4 julio 2008, p. 6.

26 "A contract is a promise or a set of promises for the breach of which the law gives a remedy, or the performance of which the law in some way recognizes as a duty." Restatement (First) of Contracts § 1 (1932). "A contract is an agreement giving rise to obligations which are enforced or recognised by law", G. TRerTel, The Law of Contract, Londres, Sweet \& Maxwell, 2003 , p. 1.

${ }^{27}$ M. RASKIN, "The Law and Legality of Smart Contracts", Georgetown Law Technology Review, vol. 1, 2017, pp. 305-341, p. 322.

${ }^{28}$ Obligatio est iuris vinculum, quo necessitate adstringimur alicuius solvendae rei secundum nostrae civitatis iura. Instituciones 3, 13 pr.

${ }^{29}$ V.gr. Artículo 1088 Código Civil español.

${ }^{30}$ A. SAVelyev, "Contract law 2.0: 'Smart' contracts as the beginning of the end of classic contract law," Information \& Communications Technology Law, vol. 26, núm. 2, 2017, pp. 116-134, p. 130. 
tariamente asumido por las partes." ${ }^{31}$ A este respecto, las partes que celebran un smart contract aceptan la fuerza vinculante de sus términos técnicos, dando su consentimiento implícito al código de programación subyacente, ${ }^{32}$ de suerte que puede considerarse que asumen voluntariamente el vínculo creado.

13. La cuestión de si se trata o no de una vinculación jurídica válida deberá determinarse conforme a la ley aplicable al contrato, siguiendo lo prescrito en el art. 10(1) Roma I.

14. Por otra parte, no cabe duda de que la contratación inteligente implica un conflicto de leyes (art.1(1) Roma I) teniendo en cuenta que esta tecnología es transfronteriza por naturaleza.

15. A tenor del art. 3(1) Roma I, las partes pueden elegir la ley aplicable al contrato, por lo que las partes de un smart contract también disponen de este derecho subjetivo, aunque la ley elegida tiene que ser una ley estatal y en vigor. La denominada Lex Cryptographia, que examinaremos más adelante, u otros ejemplos autorregulatorios similares, no pueden funcionar como ley del contrato bajo el Reglamento. La elección de ley aplicable, siguiendo los dictados del texto europeo, deberá ser expresa o tácita, pero no presunta. En un smart contract la elección podrá ir inserta en el mismo código o en un documento separado. No obstante, en el caso de existir un pacto de sumisión celebrado del mismo modo, el Reglamento obliga al juez a tener presente una posible elección de ley tácita (Considerando 12).

16. En defecto de elección la ley aplicable, y, sin perjuicio de lo que el Reglamento establece en relación con los contratos de transporte, trabajo, consumo y seguros, el art. 4(1) del Reglamento "Roma I" precisa directamente la ley aplicable al contrato para ocho categorías contractuales típicas, se determinará en consonancia con las reglas que el mismo señala. Si la relación contractual no responde a esas categorías, el contrato se regulará por la ley de la residencia habitual del prestador característico, art. 4(2). A su vez, el Reglamento permite al juez una cierta flexibilidad para aplicar otra ley que presente vínculos más manifiestamente estrechos con la situación, art. 4(3). Junto a ello, cuando la ley aplicable al contrato no pueda determinarse con arreglo a los apartados 1 y 2 del art. 4 del Reglamento "Roma I", éste se regirá por la ley del país con el que presenta los vínculos más estrechos, art. 4(4). En principio, esto significa que, en ausencia de elección de ley aplicable, un smart contract quedará sujeto a la ley de la residencia habitual del prestador característico o por la ley de los vínculos más estrechos.

17. De otro lado, cuando estemos ante smart contracts con parte débil, los arts. 5-8 del Reglamento de Roma I, permiten la elección de la ley más favorable o en su defecto, ley de la residencia habitual de la parte más débil.

18. Por lo general, tal como afirman algunos autores,$^{33}$ es posible localizar un contrato inteligente en un sistema jurídico estatal determinado, dado que el Reglamento Roma I no gira en torno al lugar

${ }^{31}$ STJCE 22 marzo 1983, Peters, 34/82, Rec. 1983, p. 987; STJCE 17 junio 1992, Handte, c-26/91, ECLI:EU:C:1992:268; STJCE 17 septiembre 2002, 334/00, Tacconi, ECLI:EU:C:2002:499; STJCE 5 febrero 2004, C-265/02, Frahuil, ECLI:EU:C:2004:77; STJCE 27 octubre 1998, C-351/96, Réunion, ECLI:EU:C:1998:242; STJUE 17 octubre 2013, C-359/12, OTP Bank, ECLI:EU:C:2014:325; STJUE 10 septiembre 2015, C-47/14, Ferho, ECLI:EU:C:2015:574; STJUE 21 enero 2016, C-359/14 y C-475/14, ERGO, ECLI:EU:C:2016:40; STJUE 21 abril 2016, C-574/14, Austro-Mechana, ECLI:EU:C:2016:286; STJUE 15 junio 2017, C-249/16, Kareda, ECLI:EU:C:2017:472; STJUE 7 marzo 2018, C-274/16, C-447/16 y C-448/16, Air Nostrum, ECLI:EU:C:2018:160.

${ }^{32}$ R. H. Weber, "Blockchain technology, smart contracts and virtual currencies", en A. De Franceschi y R. Schulze (eds.), Digital Revolution- New Challenges for Law, Munich, C.H. Beck, Nomos, 2019, pp. 299-312, p. 304.

${ }^{33}$ A. ZimmermanN, "Blockchain-Netzwerke und Internationales Privatrecht - oder: der Sitz dezentraler Rechtsverhältnisse," IPRax, vol. 6, 2018, pp. 566-573; G. RüHL, “The Law Applicable to Smart Contracts, or Much Ado About Nothing?”, Oxford Business Blog, 23 enero 2019, https://www.law.ox.ac.uk/business-law-blog/blog/2019/01/law-applicable-smart-contracts-ormuch-ado-about-nothing (consultado el 7 de diciembre de 2020); G. RüHL, "Smart contracts - Welches Recht gilt?", en T. Braegelmann y M. Kaulartz (eds), Smart Contracts, Munich, C.H. Beck, 2019, p. 147 ss.; G. RüHL, "Smart (legal) contracts, or: Which (contract) law for smart contracts?", en B. CAPPIELlo y G. CARULLO (eds.), Blockchain, Law and Governance, Springer, 2020, disponible en https://ssrn.com/abstract=3552004 (consultado el 7 de diciembre de 2020). 
de celebración ni el lugar de ejecución del contrato para determinar la legislación aplicable, sino que recurre a factores de conexión, como la elección de ley aplicable y la residencia habitual, que funcionan razonablemente bien en una sociedad globalizada y digitalizada.

19. Sin embargo, cuando un smart contract existe solamente en forma de lenguaje de programación, sin estar respaldado por un contrato subyacente fuera de la red, la ley aplicable ha de determinase exclusivamente en base al código. En este caso, la viabilidad de los puntos de conexión utilizados en el Reglamento de Roma I es cuestionable. La opacidad y anonimidad de la cadena de bloques, por ejemplo, complica la aplicación de la ley de la residencia habitual del prestador característico. Además, hay que tener en cuenta que el contrato inteligente puede haber sido generado espontáneamente por agentes electrónicos, lo que, no solo suscita dudas acerca del papel como intermediario de estos códigos,${ }^{34}$ sino que, muchas veces, ni siquiera es posible identificar al demandado.

20. La aplicación de la ley del país con los vínculos más estrechos, por otra parte, no siempre se muestra como una solución factible, ya que estos contratos operan dentro de una arquitectura descentralizada.

Un ejemplo curioso lo constituye el denominado Plantoid, un DAO completamente autónomo que se reproduce a sí mismo. Se trata de un robot u organismo sintético programado para actuar y crecer como una planta. Si un usuario aprecia las cualidades artísticas de Plantoid, puede enviar una donación en bitcoin directamente a una cartera digital propiedad de Plantoid en sí mismo. Una vez que el Plantoid ha recaudado fondos suficientes, el Plantoid oferta, selecciona y encarga a un artista la creación de un nuevo Plantoid. ${ }^{35}$ Estamos, por tanto, ante transacciones que se desarrollan en la cadena de bloques con carácter exclusivo.

Los contratos inteligentes se incorporan a la cadena de bloques de forma distribuida y deslocalizada, donde cada nodo guarda una copia idéntica de la transacción. En la red, la implicación de cada nodo es aleatoria y ningún nodo tiene control sobre los demás. En otras palabras, las transacciones realizadas con esta tecnología se encuentran en todas partes y en ninguna. Ni siquiera hay un servidor central que pueda utilizarse como punto de referencia para establecer la ubicación de los datos. ${ }^{36}$ Cuando no hay un contrato subyacente que aporte los datos necesarios para establecer la ley con los vínculos más estrechos a la situación, la solución prevista por el Reglamento de Roma I, por tanto, no parece aportar la previsibilidad y seguridad jurídica necesarias; cualquier localización de la transacción en el ordenamiento jurídico de un país concreto es puramente aleatoria.

21. De lo anterior podemos deducir que, si bien el Derecho internacional privado puede regular de forma razonable un gran número de operaciones en la cadena de bloques, sería conveniente prever una solución conflictual específica para la contratación inteligente, en aras de una mayor seguridad jurídica. ${ }^{37}$ En ausencia de elección de ley, las limitaciones de las normas actuales son evidentes en el contexto deslocalizado de la cadena de bloques, sobre todo, cuando no existe un contrato subyacente fuera de la red que respalde la transacción. Circunstancia que también se predica respecto a las cuestiones sobre competencia judicial internacional y de eficacia extraterritorial de decisiones. Aunque en una mayoría de los casos las normas existentes sobre competencia judicial internacional son aplicables, ${ }^{38}$ no

${ }^{34}$ F. Guillaume, “Aspects of private international law related to blockchain transactions”, en D. Kraus, T. Obrist y O. Hari (eds.), Blockchains, Smart Contracts, Decentralised Autonomous Organisations and the Law, Edward Elgar Publishing, 2019, pp. 49-82.

${ }^{35}$ I'm a PLANTOID: A Blockchain-Based Life Form, http://okhaos.com/plantoids (consultado el 7 de diciembre de 2020).

${ }^{36}$ D.J. B. Svantesson, Private International Law and the Internet, $3^{\mathrm{a}}$ ed., Kluwer Law International, 2016, pp. 469. En este sentido, vid. la STJUE de 19 abril 2012, C-523/10, Wintersteiger, ECLI:EU:C:2012:220, donde se afirma que el lugar de localización del servidor es difícil de prever y puede ser manipulado fácilmente (para. 36).

${ }^{37}$ En el mismo sentido, A. Ortega Giménez, "Smart Contracts" y Derecho Internacional Privado, Navarra, Thomson Reuters Aranzadi, 2019, p. 80.

${ }^{38}$ A. Ortega Giménez, "Smart Contracts” y Derecho Internacional Privado, Navarra, Thomson Reuters Aranzadi, 2019, pp. 61-68; R. Ruiz RodríGuez, "Las criptodivisas como medio de pago y el Derecho internacional privado", Cuadernos de Derecho Transnacional, vol. 12, n², octubre 2020, pp. 740-757, p. 753. 
serían operativas en todos los supuestos. Pensemos, por ejemplo, en el caso de situaciones en las que la identidad de las partes es anónima y sus activos conocidos solo existen en la cadena de bloques.

El apartado IV.1 analiza las posibles soluciones respecto a la ley aplicable.

\section{La Lex Cryptographia}

22. Los deberes y obligaciones contenidos en las normas jurídicas son potencialmente susceptibles de ser incumplidos y ello implica la necesidad de una autoridad que haga valer la ley ex post contra quienes la han infringido. Los algoritmos, por el contrario, determinan lo que se puede o no hacer desde el punto de vista técnico. El software determina ex ante el patrón de conducta y lo hace de una forma más eficaz que la ley, puesto que permite codificar disposiciones legales o contractuales en un contrato inteligente y transformarse así en código informático con "garantía de ejecución." ${ }^{39}$

23. Algunos autores vaticinan que los algoritmos terminarán por desplazar al Derecho y a jueces y tribunales marcado por la aparición de un nuevo cuerpo de normas independientes de la ley estatal. Es lo que se denomina Lex Cryptographia, entendida como el conjunto de normas que operan a través de contratos inteligentes autoejecutables y organizaciones autónomas descentralizadas. ${ }^{40}$

24. La Lex Cryptographia es vista como la extensión natural de la Lex Mercatoria ${ }^{41}$ el cuerpo de normas de diferente contenido y origen, creado por los agentes del tráfico para regular las necesidades del comercio internacional. ${ }^{42}$ De la misma manera que los comerciantes en la Edad Media crearon su particular marco normativo para escapar del Derecho canónico y feudal y, tras la Segunda Guerra Mundial, impulsaron el comercio internacional en torno al arbitraje y al desarrollo de usos y prácticas propias, los agentes del tráfico participantes en la cadena de bloques están estableciendo una serie de prácticas, costumbres particulares y principios basados en el consenso, al margen del monopolio legislativo del Estado. ${ }^{43}$

25. La Lex Mercatoria ha sido una noción polémica desde que la doctrina hablase por primera vez de su renacer en los años sesenta del pasado siglo. ${ }^{44}$ Los críticos han señalado, por ejemplo, que sus normas no son fruto de la producción legislativa de un parlamento, ni están recogidas en un convenio internacional. En este sentido, se ha incidido en que se trata de las normas de un club privado (los comerciantes) y que, en consecuencia, carecen de legitimidad democrática y de fuerza vinculante, al no contar con un aparato coercitivo que garantice su cumplimiento. ${ }^{45}$ Otros autores han sostenido que son normas vagas e incompletas, carecen de generalidad y no regulan todos los supuestos que presenta el tráfico comercial internacional, llegando incluso a negar su existencia ante su intangibilidad y vaguedad. ${ }^{46}$ Bajo

\footnotetext{
${ }^{39}$ S. Hassan y P. De Filippi, “The Expansion of Algorithmic Governance: From Code is Law to Law is Code,” Field Actions Science Reports, Número Especial 17, 2017, pp. 88-90, http://journals.openedition.org/factsreports/4518 (consultado el 7 de diciembre de 2020).

${ }^{40}$ A. Wright y P. De FiLIPPI, "Decentralized Blockchain Technology and the Rise of Lex Cryptographia" (10 de marzo de 2015), p. 4. Disponible en SSRN: https://ssrn.com/abstract=2580664 (consultado el 7 de diciembre de 2020).

${ }^{41}$ A. Wright y P. De FilipPI, "Decentralized Blockchain Technology and the Rise of Lex Cryptographia" (10 de marzo de 2015), p. 4. Disponible en SSRN: https://ssrn.com/abstract=2580664 (consultado el 7 de diciembre de 2020).

${ }^{42}$ A. M. López RodríGuez, "Lex Mercatoria", Rettid, 2002, pp. 46-56, p. 47.

${ }^{43}$ F. Guillaume, "Aspects of private international law related to blockchain transactions”, en D. Kraus, T. Obrist y O. Hari (eds.), Blockchains, Smart Contracts, Decentralised Autonomous Organisations and the Law, Edward Elgar Publishing, 2019 , pp. 49-82, p. 73.

${ }^{44}$ LORD M. MustiLl, "The new Lex Mercatoria: the first twenty-five years", Liber Amicorum for Lord Wilberforce, Oxford, 1987, pp. 86-119; B. Goldman, "Lex Mercatoria", Forum Internationale, vol. 3, 1983, p. 3; C. Schmitthoff, "International Business Law A New Law Merchant”, en C.J. Cheng (ed.), Clive M. Schmitthoff's Select Essays on International Trade Law, Martinus Nijhoff, 1988, pp. 20-37, p. 23.

${ }^{45}$ A. Kassis, Théorie Générale des Usages du Commerce, Paris, Librairie Générale de Droit et de Jurisprudence, 1984, p. 165 ss.

${ }^{46}$ F. A. MAnN, "England Rejects 'Delocalised' Contracts and Arbitration," The International and Comparative Law Quarterly, vol. 3, núm. 1, 1984, pp. 193-98.
} 
la crítica política, además, se sigue haciendo hincapié en que la Lex Mercatoria es una creación de las grandes empresas de países desarrollados para someter a los países en desarrollo. ${ }^{47}$

Desde una postura más pragmática, sin embargo, se hace referencia a la práctica del arbitraje comercial internacional, donde en determinadas circunstancias, se aplican normas no estatales, bien sea bajo la denominación de Lex Mercatoria o similares, en la resolución de controversias. ${ }^{48}$ Lo relevante, por tanto, no es tanto la discusión dogmática en torno a la Lex Mercatoria, sino determinar cuándo y cómo se aplica. ${ }^{49}$

26. La Lex Cryptographia, al igual que la Lex Mercatoria, se basa en la autorregulación. Por ello, muchos de los argumentos utilizados en la crítica a la Lex Mercatoria vuelven a repetirse a modo de déjà vue, para cuestionar la validez y autonomía de esta nueva forma de gobernanza digital.

27. Desde la doctrina anglosajona, por ejemplo, se alega que la Lex Cryptographia no puede desplazar a la ley porque, a diferencia de esta, carece de mecanismos coercitivos de ejecución ex post. Y es que, no olvidemos, la noción de contrato en el common law va indisolublemente asociada a la accionabilidad..$^{50}$

28. Bajo otro punto de vista, se afirma que estas normas de carácter técnico no pueden reemplazar a la ley tradicional por su carácter incompleto y su falta de normatividad. En primer lugar, porque los algoritmos no pueden anticipar todas las vicisitudes y complejidades que se pueden presentar en un contrato y es imposible en el estado actual de la tecnología crear un código que incluya respuestas para todas las situaciones posibles que podrían resultar de la relación entre dos o más partes. ${ }^{51}$ En segundo lugar, porque el Derecho o los contratos tradicionales no tienen solamente funciones ejecutivas. Se trata de mecanismos sociales diseñados para preservar el orden público y la seguridad nacional, así como los intereses de la esfera privada, caracterizada por la necesidad de apoyar el crecimiento económico, promover la autonomía individual y los derechos fundamentales. ${ }^{52}$ Los códigos informáticos son capaces de representar términos que son expresiones de la lógica, pero a diferencia de la Ley, no van dirigidos a organizar la Sociedad ni están fundamentados en conceptos como la razón o la conciencia. ${ }^{53}$

29. De otro lado, se señala que la implementación arquitectónica de estas tecnologías depende de las opciones específicas de los operadores de plataformas e ingenieros de software quienes, en último término, buscan promover o prevenir cierto tipo de acciones. Al igual que cualquier otro artefacto tecnológico, el código no es neutral. Tiene importantes implicaciones ideológicas, en la medida en que puede apoyar ciertas políticas o facilitar determinadas acciones y comportamientos sobre otros. ${ }^{54}$ Además, con

${ }^{47}$ J. Hernández Zubizarreta y P. Ramiro, "Against the Lex Mercatoria. Proposals and alternatives for controlling transnational corporations”, Observatory of multinationals in Latin America (OMAL), 2016, https://omal.info/IMG/pdf/against_lex_ mercatoria.pdf (consultado el 7 de diciembre de 2020).

${ }^{48}$ A. L. Calvo Caravaca y J. Carrascosa González, "Lex Mercatoria and Private International Arbitration", Cuadernos de Derecho Transnacional, vol. 12, $\mathrm{n}^{\circ} 1,2020$, pp. 66-85.

${ }^{49}$ Vid., por ejemplo, A. M. López Rodríguez, Lex Mercatoria and Harmonization of Contract Law in the EU, Copenhague, DJØF Publishing, 2003; F. DASSER, Internationale Schiedsgerichte und Lex Mercatoria. Rechtsvergleichender Beitrag zur Diskussion über ein nicht-staatliches Handelsrecht, Schweizer Studien zum internationalen Recht, Band 59, Zürich, Schulthess Verlag, 1989.

${ }^{50}$ K. Werbach y N. Cornell, “Contracts Ex Machina,” Duke Law Journal, vol. 67, 2017, pp. 313-382, p. 319

${ }^{51}$ S. Agnikhotram y A. Kouroutakis, "Doctrinal challenges for the legality of smart contracts: Lex Cryptographia or a new, 'smart' way to contract?”, Journal of High Technology Law, vol. 19, núm. 2, 2019, pp. 300-328, p. 319.

${ }^{52}$ S. Hassan y P. De Filippi, "The Expansion of Algorithmic Governance: From Code is Law to Law is Code," Field Actions Science Reports, Número Especial 17, 2017, pp. 88-90, http://journals.openedition.org/factsreports/4518 (consultado el 7 de diciembre de 2020).

${ }^{53}$ S. Farrell, H. Machin y R. Hinchliffe, "Lost and found in smart contract translation - considerations in transitioning", King \& Wood Mallesons, 2017, p. 3. https://www.uncitral.org/pdf/english/congress/Papers_for_Programme/14-FARRELL_ and_MACHIN_and_HINCHLIFFE-Smart_Contracts.pdf

${ }^{54}$ S. Hassan y P. De FilipPI, "The Expansion of Algorithmic Governance: From Code is Law to Law is Code," Field Actions Science Reports, Número Especial 17, 2017, pp. 88-90, p. 89 http://journals.openedition.org/factsreports/4518 (consultado el 7 de diciembre de 2020). 
la ayuda de la IA los algoritmos y normas técnicas pueden personalizarse y adaptarse al perfil de cada individuo, quebrando con ello los principios básicos de universalidad, generalidad y no discriminación que caracterizan a la Ley tal como la conocemos..$^{55}$ Estaríamos, entonces, ante lo que se ha denominado gobernanza algorítmica: "un nuevo sistema normativo capaz de regular la sociedad de manera más eficiente, que reduce los costes de la aplicación de la ley y permite un sistema de normas personalizado para cada ciudadano, donde las reglas se revisan constantemente en función de las preferencias y perfiles correspondientes. ${ }^{.56}$ En definitiva, una especie de régimen totalitario moderno. ${ }^{57}$

30. Los partidarios de la Lex Cryptographia, por otra parte, afirman que esta tiene una funcionalidad similar a las instituciones jurídicas, puesto que contiene normas acordadas por las partes que son ejecutables, no por las autoridades estatales, sino mediante herramientas tecnológicas. Por tanto, puede realizar tareas tradicionalmente reservadas al Derecho y de forma más eficiente. Ya existen algunas plataformas como Legalese, ${ }^{58}$ Kleros $^{59}$ o The Aragon Network ${ }^{60}$ que se anuncian como alternativas al Derecho y al sistema judicial. Esta última, por ejemplo, pretende ser una "jurisdicción digital" que pone a disposición de las partes un catálogo de estatutos y regulaciones para que puedan ser implementadas como normativa interna en las organizaciones autónomas descentralizadas (DAOs). Además, estas plataformas contienen sistemas de resolución de conflictos independientes de cualquier jurisdicción nacional, punto en el que la Lex Cryptographia difiere de la Lex Mercatoria, ya que las decisiones arbitrales sí que están sujetas, en último término, al escrutinio de jueces y tribunales. Según sus impulsores, este sistema se adapta mejor a la interdependencia y descentralización de la nueva realidad tecnológica, puesto que proporciona a las partes "un sistema judicial descentralizado en línea que no está sujeto a barreras artificiales tradicionales como las jurisdicciones nacionales". ${ }^{61}$

31. Algún autor ha apuntado a que la solución óptima a la problemática que plantean los contratos inteligentes puede estar en la incipiente Lex Cryptographia y en la resolución de conflictos en línea, ${ }^{62}$ e incluso se vaticina que los algoritmos terminarán por desplazar a la Ley y a jueces y tribunales, una vez se consolide la Lex Cryptographia. ${ }^{63}$

32. En el estado actual de desarrollo de la Lex Cryptographia, sin embargo, la intervención del Derecho estatal sigue siendo necesaria para solucionar situaciones no previstas por el código algorítmico tales como errores de programación, validez o causas extrínsecas, tales como insolvencias, fallecimientos o activos criptográficos hackeados u obtenidos ilegalmente. ${ }^{64}$ Sin olvidar que, ante supuestos de daños causados por estas tecnologías, el legislador ha de actuar para proporcionar a la víctima una compensación adecuada.

${ }^{55}$ S. Hassan y P. De Filippi, “The Expansion of Algorithmic Governance: From Code is Law to Law is Code," Field Actions Science Reports, Número Especial 17, 2017, pp. 88-90, p. 89, http://journals.openedition.org/factsreports/4518 (consultado el 7 de diciembre de 2020).

${ }^{56}$ A. Wright y P. De FiLIPPI, "Decentralized Blockchain Technology and the Rise of Lex Cryptographia” (10 marzo 2015), p. 4. Disponible en SSRN: https://ssrn.com/abstract=2580664 (consultado el 7 de diciembre de 2020).

${ }^{57}$ A. Wright y P. De FiLIPPI, "Decentralized Blockchain Technology and the Rise of Lex Cryptographia" (10 marzo 2015), p. 43. Disponible en SSRN: https://ssrn.com/abstract=2580664 (consultado el 7 de diciembre de 2020).

${ }^{58} \mathrm{https}$ ://legalese.com (consultado el 7 de diciembre de 2020).

${ }^{59} \mathrm{https} / / /$ kleros.io (consultado el 7 de diciembre de 2020).

${ }^{60} \mathrm{https}: / /$ aragon.org (consultado el 7 de diciembre de 2020).

${ }^{61} \mathrm{https}: / /$ docs.ethhub.io/built-on-ethereum/governance/aragon (consultado el 7 de diciembre de 2020).

${ }^{62}$ F. Guillaume, “Aspects of private international law related to blockchain transactions”, en D. Kraus, T. OBrist y O. Hari (eds.), Blockchains, Smart Contracts, Decentralised Autonomous Organisations and the Law, Edward Elgar Publishing, 2019 , pp. 49-82, p. 71 ss.

${ }^{63}$ A. Wright y P. De FiLIPPI, "Decentralized Blockchain Technology and the Rise of Lex Cryptographia” (10 marzo 2015), p. 4. Disponible en SSRN: https://ssrn.com/abstract=2580664 (consultado el 7 de diciembre de 2020).

${ }^{64}$ M. Lehmann, "Who owns Bitcoin? Private Law Facing the Blockchain", EBI Working Papers Series, núm. 42, 2019, https://papers.ssrn.com/sol3/papers.cfm?abstract_id=3402678 (consultado el 7 de diciembre de 2020). 
33. Pero, insistimos, cuando las partes implicadas solo tienen activos dentro de la red, y/o su identidad es difícil de establecer, la capacidad del ordenamiento jurídico estatal para intervenir es limitada.

\section{Equilibrio entre legislación y autorregulación. El papel del Derecho internacional privado}

34. El legislador no puede permanecer ajeno al fenómeno de la Lex Criptographia. No se trata de una lucha por ver si esta puede reemplazar a la ley, sino de encontrar puntos de encuentro y articular posibles fricciones. Unos pocos países ya han tomado cartas en el asunto y empiezan a legislar en materia de blockchain y contratación inteligente. ${ }^{65}$ La Unión Europea, asimismo, está impulsando iniciativas regulatorias en distintos campos. Por ejemplo, recientemente ha lanzado una Propuesta de Reglamento sobre los mercados de criptoactivos. ${ }^{66}$ También son destacables la creación de una sandbox para probar casos de uso de blockchain y activos digitales en la Infraestructura Europea de Servicios Blockchain $(E B S I)^{67}$ y la batería de acciones específicas presentadas dentro de la estrategia de la Comisión Europea para un Mercado Único Digital. ${ }^{68}$

35. Los expertos en nuevas tecnologías digitales parecen coincidir en la necesidad de tener en cuenta algunos aspectos concretos a la hora de legislar en la materia. Se menciona, por ejemplo, la necesidad de encontrar un equilibrio entre innovación tecnológica y protección ${ }^{69}$ y el desfase de velocidad entre el desarrollo tecnológico y normativo. ${ }^{70} \mathrm{~A}$ su vez, se apuesta por la adopción de definiciones sencillas, pero (técnicamente) utilizables y la amplia difusión de las interpretaciones legales de los conceptos que se regulen. ${ }^{71}$ Pero, sobre todo, se insiste el carácter transfronterizo de estas herramientas. ${ }^{72}$

36. La cadena de bloques y los contratos inteligentes están estrechamente relacionados con Internet y diseñados para ser omnipresentes y universales. No sólo carecen de presencia física; también son intrínsecamente transnacionales. Por ello, es crucial que regulación esté lo más alineada posible en los distintos países, empezando por la Unión Europea y de cara a la construcción del Mercado Único Digital. ${ }^{73}$ Incluso se aboga por la oportunidad de que, en el futuro, las autoridades internacionales lleguen

${ }^{65}$ Por ejemplo, algunos Estados en los Estados Unidos han adoptado legislación en la materia. También existen iniciativas legislativas al respecto en el Reino Unido, Italia, Francia, Suiza, Malta, Japón, Islas Bermudas, Mónaco, Gibraltar, Bahrein o Tailandia, "Blockchain Regulations: Recent Key Developments," Zigurat, Global Institute of Technology, https://www.ezigurat.com (consultado el 4 de diciembre de 2020).

${ }^{66}$ Propuesta de Reglamento del Parlamento Europeo y del Consejo relativo a los mercados de criptoactivos y por el que se modifica la Directiva (UE) 2019/1937, COM(2020) 593 final, de 24 de septiembre de 2020.

${ }^{67}$ EBSI es una iniciativa conjunta de la Comisión Europea y la Asociación Europea de Blockchain (EBP) que tiene como objetivo brindar servicios públicos digitales transfronterizos en toda la UE utilizando tecnología blockchain; https://ec.europa. eu/digital-single-market/en/legal-and-regulatory-framework-blockchain (consultado el 7 de diciembre de 2020).

${ }^{68}$ Comunicación de la Comisión al Parlamento Europeo, al Consejo, al Comité Económico y Social Europeo y al Comité de las Regiones: Una Estrategia para el Mercado Único Digital de Europa, COM(2015) 192 final, de 6 de mayo de 2015.

${ }^{69}$ V.gr. T. Lyons, L. CourCelas y K. Timsit, Legal and regulatory framework of blockchains and smart contracts, https:// www.eublockchainforum.eu/sites/default/files/reports/report_legal_v1.0.pdfInforme, p. 34 (consultado el 7 de diciembre de 2020); Dirección General de Justicia y Consumidores (Comisión Europea), Report on Liability for Artificial Intelligence and Other Emerging Digital Technologies, 2019, https:/op.europa.eu/es/publication-detail/-/publication/1c5e30be-1197-11ea8c1f-01aa75ed71a1, p. 27 (consultado el 7 de diciembre de 2020).

${ }^{70}$ S. Agnikhotram y A. Kouroutakis, "Doctrinal challenges for the legality of smart contracts: Lex Cryptographia or a new, ‘smart' way to contract?”, Journal of High Technology Law, vol. 19, núm. 2, 2019, pp. 300-328, p. 326.

${ }^{71}$ Report on Liability for Artificial Intelligence and Other Emerging Digital Technologies, 2019, https://op.europa.eu/es/ publication-detail/-/publication/1c5e30be-1197-11ea-8c1f-01aa75ed71a1, p. 27 (consultado el 7 de diciembre de 2020); "La regulación de Blockchain y los Smart contracts va a requerir la armonización de conceptos, principios, regulación e interpretaciones", Especial Directivos, núm. 1765, 1 de noviembre de 2019, pp. 38-42, p. 40.

${ }^{72}$ F. MösLein, “Legal Boundaries of Blockchain Technologies: Smart Contracts as Self-Help?”, en A. De Franceschi y R. Schulze (eds.), Digital Revolution - New Challenges for Law, Munich, C. H. Beck, 2019, pp. 313-326, p. 316.

${ }^{73}$ T. Lyons, L. CourCelas y K. Timsit, Legal and regulatory framework of blockchains and smart contracts, https://www. eublockchainforum.eu/sites/default/files/reports/report_legal_v1.0.pdfInforme, p. 34 (consultado el 7 de diciembre de 2020). 
a un consenso y procedan a una modificación del marco normativo que unifique el tratamiento legal de las mismas. ${ }^{74}$

37. Ciertamente, se necesita un enfoque lo más uniforme posible que busque aprovechar los beneficios de eficiencia, rapidez y rendimiento de estas tecnologías y sea capaz de proporcionar seguridad, protección y certeza. Sin embargo, la experiencia demuestra lo lento y complejo que es armonizar el Derecho sustantivo a nivel internacional. Por ello, creemos que, en primer término, la innovación normativa en materia de contratación inteligente debe venir de la mano del Derecho internacional privado.

38. Teniendo en cuenta la velocidad de la innovación tecnológica y la rápida aparición de nuevas aplicaciones, el legislador nacional y, sobre todo, el internacional, corre el riesgo de no poder estar al día y terminar creando una maraña de medidas confusas y potencialmente divergentes. Por otra parte, intervenir demasiado pronto puede ser contraproducente, siendo preferible respaldar los esfuerzos autorreguladores de la industria y esperar a que esta tecnología tenga un cierto rodaje antes de legislar. ${ }^{75}$ En este contexto, el Derecho internacional privado puede erigirse como garante de la seguridad jurídica y de los mecanismos de protección de los consumidores, inversores, y de la competencia en el mercado, fomentando, al mismo tiempo, el desarrollo de las mejores soluciones a nivel legislativo e incentivando la innovación tecnológica.

\section{Seguridad jurídica. Autonomía de las partes y lex fori}

39. El principio de la autonomía de la voluntad conflictual, recogido en el art. 3 Roma I y reconocido por la mayoría de ordenamientos jurídicos, es la mejor forma de garantizar la seguridad jurídica de los smart contracts, ya que la elección de la ley aplicable por las partes evita controversias respecto al marco jurídico que rige el contrato, facilita la labor del juez y permite a las partes diseñar su relación jurídica conforme al Derecho sustantivo que mejor se adapta a sus intereses. ${ }^{76}$

40. Siguiendo lo previsto en el art. 3(5), en relación con el art. 10(1) Roma I, la ley elegida deberá ser la de un Estado que dé validez a la contratación inteligente, para que la transacción pueda tener un efecto jurídicamente vinculante.

41. La elección de la ley aplicable puede realizarse conjuntamente con un pacto de sumisión o en solitario y puede insertarse en el contrato subyacente que "respalda" a un smart contract, en el propio contrato inteligente, o en los términos y condiciones generales de la cadena de bloques. ${ }^{77}$ Esta última posibilidad es muy atractiva, sin lugar a duda, puesto que garantiza a todos los agentes que operan en una red determinada el grado necesario de seguridad jurídica frente a exigencias legales inesperadas que invalidan el contrato o imposibilitan su ejecución. En consecuencia, abogamos por que desarrolladores y agentes promuevan los pactos de sumisión y de elección de ley aplicable tanto a nivel de red como a nivel individual.

42. Una cuestión que puede plantearse es si la elección de las normas y prácticas de una red o "jurisdicción online" como Derecho aplicable pueden funcionar como lex causae. Aplicando de forma analógica lo establecido para la Lex Mercatoria ${ }^{78}$ podemos distinguir las siguientes situaciones:

${ }^{74}$ F. MösLein, "Legal Boundaries of Blockchain Technologies: Smart Contracts as Self-Help?”, en A. De FrancESCHI y R. Schulze (eds.), Digital Revolution - New Challenges for Law, Munich, C. H. Beck, 2019, pp. 313-326, p. 316.

${ }^{75}$ T. Lyons, L. CourCelas y K. TIMSIT, Legal and regulatory framework of blockchains and smart contracts, https://www. eublockchainforum.eu/sites/default/files/reports/report_legal_v1.0.pdfInforme, p. 34 (consultado el 7 de diciembre de 2020).

${ }^{76}$ A. L. Calvo Caravaca y J. Carrascosa González (directores), Derecho internacional privado, Vol. II, $18^{\mathrm{a}}$ ed., Granada, Comares, 2018, p. 959.

${ }^{77}$ F. Guillaume, “Aspects of private international law related to blockchain transactions”, en D. Kraus, T. Obrist y O. Hari (eds.), Blockchains, Smart Contracts, Decentralised Autonomous Organisations and the Law, Edward Elgar Publishing, 2019, pp. 49-82, p. 79.

${ }^{78}$ A. L. Calvo Caravaca y J. Carrascosa González (directores), Derecho internacional privado, Vol. II, $18^{\mathrm{a}}$ ed., Granada, Comares, 2018, p. 937. 
- A nivel no contencioso: las partes pueden referirse en sus contratos a las prácticas y costumbres reconocidas por los participantes en la cadena de bloques y ajustar su proceder conforme a estas.

- A nivel contencioso, en una plataforma de resolución de conflictos online de una "jurisdicción digital": la controversia se resolverá, dependiendo de la plataforma en cuestión, bien por todos los miembros de la comunidad, bien por un órgano compuesto por miembros elegidos por los participantes, ya sea a título consultivo, ya sea mediante una decisión adoptada por votación, pero con arreglo a las normas elegidas por las partes para solventar el litigio. La incidencia del Derecho estatal en este caso es prácticamente inexistente, especialmente, si la decisión ha de ejecutarse directamente en la red.

- A nivel contencioso judicial: De conformidad con lo establecido en el Considerando 13 del Reglamento Roma I, la controversia ha de decidirse conforme al Derecho estatal aplicable. La elección por las partes de la Lex Cryptographia solo tendrá efecto en la medida y con el alcance que permita la ley estatal aplicable en defecto de lección.

43. El problema surge a la hora de determinar la ley aplicable en defecto de elección, bien porque las partes no hayan acordado nada al respecto, bien porque la elección no sea válida. La solución prevista en el Reglamento Roma I gira fundamentalmente en torno a la ley del país de la residencia habitual del prestador característico y a la ley del país los vínculos más estrechos con la situación. En principio, estas conexiones son lo suficientemente flexibles como para poder ser aplicadas a la mayoría de contratos inteligentes, especialmente, cuando estos tienen un respaldo fuera de la red. Como se apunta en el apartado II de este trabajo, las complicaciones aparecen cuando el contrato inteligente solo existe en forma de código, puesto que la opacidad y deslocalización de la cadena de bloques impiden la identificación de las partes y la localización de la transacción en el ordenamiento de un país determinado. Todo intento de establecer la ley del país de los vínculos más estrechos choca con la imposibilidad intrínseca de establecer la ubicación geográfica de las transacciones en la cadena de bloques. Ni siquiera sería posible seguir la solución prevista por el Convenio de la Haya sobre Ley Aplicable a Ciertos Derechos sobre Valores Depositados en un Intermediario, ${ }^{79}$ cuyo art. 5 remite, en defecto de elección, a la ley del país donde el intermediario relevante mantiene la cuenta de valores. En la cadena de bloques cualquier conexión a la ubicación de la cuenta del usuario es demasiado superficial y aleatoria, ya que implica establecer la ubicación de su clave privada. Si ya es difícil en la práctica determinar la ubicación de una cuenta de valores con intermediario, aún lo es más establecer la ubicación de una cartera digital. Por ello, entendemos que la solución más práctica y previsible en estos casos, a la vez que la menos arbitraria, es la aplicación de la lex fori. ${ }^{80}$

44. Ante la ausencia de un cuerpo legislativo uniforme a nivel global, el Derecho internacional privado puede jugar un papel central en la consolidación y desarrollo de la contratación inteligente. El principio de la autonomía de la voluntad conflictual permite a las partes el establecimiento claro de la ley aplicable, garantizando así un grado mínimo de seguridad jurídica. Se trata, además, de un principio que casa a la perfección con el deseo de libertad individual pretendido por los usuarios de la blockchain. Esto implica dejar el mayor espacio posible a la autonomía de la voluntad y promover la elección de la ley y los pactos de sumisión dentro de la cadena de bloques. Al mismo tiempo, la aplicación de la lex fori en ausencia de elección, cuando la deslocalización de la transacción impida establecer razonablemente la ley del país con las conexiones más estrechas, constituye una solución que aporta seguridad jurídica y previsibilidad. Ambas soluciones pueden convertirse, además, en sendos incentivos para el adecuado desarrollo normativo de la contratación inteligente. Efectivamente, las partes suelen elegir el ordena-

\footnotetext{
${ }^{79}$ Convenio de la Haya de 5 de julio de 2006 sobre la Ley Aplicable a Ciertos Derechos sobre Valores Depositados en un Intermediario, https://assets.hcch.net/docs/da29273b-7ab5-45b4-bb5e-b3c82b41712b.pdf.

${ }^{80}$ En el mismo sentido vid. F. Guillaume, "Aspects of private international law related to blockchain transactions", en D. Kraus, T. Obrist y O. Hari (eds.), Blockchains, Smart Contracts, Decentralised Autonomous Organisations and the Law, Edward Elgar Publishing, 2019, pp. 49-82, p. 80.
} 
miento que consideran más atractivo para regular sus intereses y se someten, en muchas ocasiones, al que entienden es el mejor tribunal por lo avanzado de su ordenamiento (better court). ${ }^{81}$ Ello se produce dentro de una situación de competencia regulatoria entre ordenamientos, que puede conducir, en último término, a reformas legislativas óptimas, tal como se examina en el siguiente apartado.

\section{Competencia regulatoria y desarrollo tecnológico}

\section{A) Competencia regulatoria}

45. En el contexto federal estadounidense de la década de 1970, $\mathrm{KITCH}^{82}$ desarrolló la Teoría de la Elección Pública, que rechaza el argumento tradicional de que la diversidad regulatoria conduce a restricciones del comercio interestatal y que, por lo tanto, dificulta la integración. Según este autor, la competencia entre distintos sistemas jurídicos genera una asignación eficiente de recursos dentro del mercado y lo hace con menor costo que la uniformidad legislativa impuesta por una autoridad central. Por lo tanto, la regulación centralizada "debe ser lo más pequeña posible para maximizar la diversidad de opciones, así como para promover la máxima competencia entre los distintos sistemas sobre sus leyes, prácticas y procedimientos. ${ }^{" 83} \mathrm{~A}$ largo plazo, este sistema puede favorecer el comercio mucho más que una autoridad centralizada porque otorga a cada ordenamiento mayores incentivos para que adopte normas eficientes tanto para su comercio interno como externo. ${ }^{84}$

46. La teoría de KIтch ha sido posteriormente desarrollada en el denominado Modelo de Competencia Regulatoria ${ }^{85}$ que aboga por una regulación descentralizada. Este modelo parte de la idea de que el Derecho se puede considerar como un producto y los operadores, consumidores de ese producto. En la medida en que existen diferentes regulaciones, cada regulador se convierte en oferente de una normativa determinada que compite en el "mercado de productos legales," donde los operadores eligen la norma que mejor se adapta a sus necesidades ${ }^{86} \mathrm{La}$ existencia de una regulación descentralizada tiene, a este respecto, varias ventajas, entre otras cosas, que permite la diversidad y la competencia. ${ }^{87}$ Los operadores pueden someterse a la normativa que mejor se adapte a las características específicas de su transacción, al mismo tiempo que la presión competitiva obliga al legislador a promulgar normas eficaces. En última instancia, esta competencia desembocará en la armonización gradual del marco regulatorio.

47. La existencia de un mercado regulatorio presupone dos condiciones básicas: la libre circulación de recursos y la ausencia de externalidades transfronterizas. ${ }^{88}$ Sin embargo, la competencia entre

${ }^{81}$ A. L. Calvo Caravaca y J. Carrascosa González (directores), Derecho internacional privado, Vol. II, $18^{\mathrm{a}}$ ed., Granada, Comares, 2018, p. 751.

${ }^{82}$ E. КітсH, "Regulation and the American Common Market," en A. D. TARLOCK (ed.), Regulation, Federalism and Interstate Commerce, Cambridge, Mass., Oelgeschlager, Gunn \& Hain, Publishers, Inc., 1981, pp. 7-55.

${ }^{83}$ E. KIтCH, "Regulation and the American Common Market," en A. D. TARLOCK (ed.), Regulation, Federalism and Interstate Commerce, Cambridge, Mass., Oelgeschlager, Gunn \& Hain, Publishers, Inc., 1981, p. 12.

${ }^{84}$ E. KITCH, "Regulation and the American Common Market," en A. D. TARLOCK (ed.), Regulation, Federalism and Interstate Commerce, Cambridge, Mass., Oelgeschlager, Gunn \& Hain, Publishers, Inc.,1981, p. 14.

${ }^{85}$ J.P. TRACHTMAN, "International Regulatory Competition, Externalization and Jurisdiction", Harvard International Law Journal, vol. 34, 1993, pp. 47-104.; W. Bratton, J. Mccahery, S. Рicciotto y C. Scott, Regulatory Competition and Coordination: Strategies and Debates of Economic Regulation in Europe and in the USA, Oxford, Clarendon Press, 1997; F. Garcimartín AlfÉrez, "Regulatory Competition: A Private International Law Approach", European Journal of Law and Economics, vol. 8, 1999, pp. 251-270.

${ }^{86}$ R. Romano, "Law as a Product: Some Pieces of the Incorporated Puzzle", Journal of Law, Economics and Organization, vol. 1, 1985, p. 225-283; R. SACCO, "Il Sistema di Diritto Privato Europeo: Le Premese per un Codice Europeo", en L. MocCIA, Il Diritto Privato Europeo: Problemi e Prospettive, Milán, Guiffrè, 1993, p. 87 ss.

${ }^{87}$ F. Garcimartín AlfÉrez, "Regulatory Competition: A Private International Law Approach", European Journal of Law and Economics, vol. 8, 1999, p. 258-259.

${ }^{88}$ F. Garcimartín Alférez, "Regulatory Competition: A Private International Law Approach", European Journal of Law and Economics, vol. 8, 1999, p. 258-259. 
sistemas regulatorios no siempre es eficiente. En ámbitos en los que están en juego valores de política pública, por ejemplo, la protección de los consumidores, puede ser necesaria una intervención legislativa. De lo contrario, se produce una "carrera hacia el mínimo común denominador", que resulta en una degradación de los estándares de protección, que a la larga eliminan las ventajas competitivas. ${ }^{89}$ Por lo tanto, la competencia regulatoria sólo es viable respecto de normas que facilitan el uso de la autonomía de las partes y la libertad de mercado. ${ }^{90}$ Es aquí donde los operadores pueden presionar al legislador para que regule de manera eficiente, ya que de lo contrario, someterán sus transacciones a otras normas.

48. En consecuencia, frente a cualquier armonización sustantiva prematura, el Derecho internacional privado y, en particular, el reconocimiento generalizado del principio de la autonomía de la voluntad, pueden propiciar, en último término, una regulación de la contratación inteligente innovadora y efectiva a nivel global.

\section{B) Equilibrio entre regulación y desarrollo tecnológico. Interacción con la Lex Cryptographia}

49. La autonomía de la voluntad también tiene otro efecto beneficioso. Una de las máximas preocupaciones de los expertos es encontrar el equilibrio necesario entre la intervención del legislador y la innovación tecnológica. ${ }^{91}$ Una regulación que genera incertidumbre tiene un impacto negativo sobre la innovación, como también lo tiene una regulación que exige a las empresas dedicar buena parte de sus recursos a su cumplimiento. ${ }^{92}$ Por ello, es preferible que el legislador adopte una postura más flexible, que favorezca la autorregulación y de más libertad a las empresas para elegir la alternativa más favorable para cumplir con la regulación, siendo en último término el mercado el que seleccione la solución más viable comercialmente.

50. Para el análisis económico del Derecho, las instituciones jurídicas y su evolución han surgido para economizar los costes de transacción, entendidos como todos aquellos costes que impiden o reducen las posibilidades de transacciones fluidas..$^{93}$ En este contexto, un sistema normativo eficiente es aquel que elimina los costes de transacción en la medida que controla los comportamientos oportunistas. ${ }^{94}$

51. Desde una perspectiva neoinstitucionalista, ${ }^{95}$ las transacciones pueden clasificarse en 1) no específicas; 2) ocasionales de carácter mixto y altamente específico y 3) transacciones frecuentes de carácter mixto y altamente específico. En el caso de transacciones no específicas, como puede ser una compraventa de mercaderías genéricas, el mercado es la forma más eficiente de gobernanza. ${ }^{96}$ Por el contrario, las transacciones ocasionales de carácter mixto y altamente específico, como pueden ser grandes proyectos industriales o tecnológicos, dependen de otras formas de gobernanza además del mercado, ya que el carácter ocasional de la transacción no permite amortizar los costes de estructuras de gestión como acuerdos

${ }^{89}$ N. ReICH, "Competition between legal orders: A New Paradigm of EC Law? Common Market Law Review, vol. 29, núm. 5, 1992, pp. 861-868.

${ }^{90}$ S. GRundmanN, "The Structure of European Contract Law", European Review of Private Law, vol. 4, 2001, pp. 505-528, p. 515.

${ }^{91}$ V.gr. Report on Liability for Artificial Intelligence and Other Emerging Digital Technologies, 2019, https://op.europa. eu/es/publication-detail/-/publication/1c5e30be-1197-11ea-8c1f-01aa75ed71a1, p. 27 (consultado el 7 de diciembre de 2020).

${ }^{92}$ Fundación Cotec para la Innovación Tecnológica, Impacto de la regulación sobre la innovación, 2014, p. 45, disponible en http://informecotec.es/media/J21_Impac_Regu_Innov.pdf (consultado el 7 de diciembre de 2020).

${ }_{93}^{93}$ P. Burrows y C. G. Veljanovski, The Economic Approach to Law, Londres, Butterworths, 1981, p. 22 ss.

${ }^{94}$ En la teoría económica un comportamiento oportunista se define como "el esfuerzo por materializar una ganancia individual sin que la transacción se lleve a cabo con franqueza u honestidad”, P. Burrows y C. G. VelJanovski, The Economic Approach to Law, Londres, Butterworths, 1981, p. 24.

${ }^{95}$ O. E. Williamson, "Contract analysis: The Transaction Costs Approach", en P. Burrows y C. G. Veluanovski, The Economic Approach to Law, Londres, Butterworths, 1981, p. 39 ss., p. 50.

${ }^{96}$ O. E. Williamson, "Contract analysis: The Transaction Costs Approach", en P. Burrows y C. G. Veljanovski, The Economic Approach to Law, Londres, Butterworths, 1981, p. 39 ss., p. 51. 
de cooperación, fusiones etc., ${ }^{97}$ como ocurre en las transacciones frecuentes de carácter mixto y altamente específico. ${ }^{98}$ Así pues, una gran mayoría de transacciones tiene lugar sin necesidad de la asistencia de mecanismos externos de reducción de costes de transacción como puede ser la normativa contractual.

52. Los smart contracts son un buen ejemplo de aplicación tecnológica que garantiza la cooperación entre dos o más partes de una transacción, sin apoyarse en ningún trasfondo jurídico o social común que garantice la ejecución del contrato. En este sentido, si se tiene en cuenta las posibles ganancias y pérdidas de eficiencia derivadas de la contratación en entornos sin confianza, la teoría económica apuesta por los contratos inteligentes frente a otros métodos de gobernanza. ${ }^{99}$ En verdad, por sus características de inmutabilidad, autoejecutabilidad, anonimidad etc. los contratos inteligentes pueden proporcionar suficientes salvaguardias en entornos sin confianza, siempre que los desarrolladores logren replicar las características del Derecho contractual en código de programación y con el mecanismo de consenso de blockchain. ${ }^{100}$ De esta forma, la intervención del legislador puede quedar reducida a garantizar la permanencia de medidas de seguridad como, por ejemplo: (i) Normas imperativas que subsanen las deficiencias del mercado; (ii) Mecanismos de protección, incluyendo a los consumidores, inversores, y protección de la competencia en el mercado; (iii) Medidas para mantener determinadas actividades dentro de los límites socialmente permitidos (límites a la financiación del terrorismo o al blanqueo de capitales); (iv) Respuestas a las necesidades sociales, ubicación de los activos importantes para su embargo etc. ${ }^{101}$ En todo lo demás, la regulación puede ser innecesaria e incluso contraproducente.

53. La incursión de la economía en el ámbito jurídico no está exenta de críticas. La verdad es que, a pesar de su lógica, la teoría económica subyacente es cambiante y hay una creciente evidencia empírica de que los individuos, a menudo, no responden al paradigma del homo economicus, por lo que la oportunidad de construir modelos basados en suposiciones que no reflejan la realidad, es cuestionable. ${ }^{102}$ Pero todavía se puede afirmar que la teoría de la elección racional, aunque imperfecta, ofrece perspectivas atractivas en muchas situaciones, ${ }^{103}$ y puede servir como herramienta de apoyo para el legislador en la tarea de regular la contratación inteligente. Si tenemos en cuenta la teoría económica, por tanto, todo apunta a que la ley preferida por los operadores será posiblemente aquella que favorezca la autorregulación y refleje un equilibrio óptimo entre innovación tecnológica y control. Así las cosas, la autonomía de las partes se muestra no sólo como un elemento útil para determinar la ley aplicable a los contratos inteligentes y aportar seguridad jurídica. También puede contribuir a informar los procesos de reforma legislativa en su grado justo.

54. La observancia de las medidas legislativas que se adopten para salvaguardar la seguridad, la protección de los consumidores, la competencia en el mercado, dar respuesta a las necesidades sociales o prohibir ciertas actividades, queda, además, garantizada, en los contratos con parte débil, a través de

${ }^{97}$ O. E. Williamson, "Contract analysis: The Transaction Costs Approach”, en P. Burrows y C. G. Veljanovski, The Economic Approach to Law, Londres, Butterworths, 1981, p. 39 ss., p. 52.

${ }^{98}$ O. E. Williamson, "Contract analysis: The Transaction Costs Approach", en P. Burrows y C. G. Veljanovski, The Economic Approach to Law, Londres, Butterworths, 1981, p. 39 ss., p. 52.

${ }^{99}$ H. EenmaA-Dimitrieva y M. J. Schmidt-Kessen, "Creating markets in no-trust environments: The law and economics of smart contracts," Computer Law \& Security Review: The International Journal of Technology Law and Practice, 2018, https:// doi.org/10.1016/j.clsr.2018.09.003.

${ }^{100}$ H. EenmaA-Dimitrieva y M. J. Schmidt-Kessen, "Creating markets in no-trust environments: The law and economics of smart contracts," Computer Law \& Security Review: The International Journal of Technology Law and Practice, 2018, https:// doi.org/10.1016/j.clsr.2018.09.003.

${ }^{101}$ H. EenmaA-Dimitrieva y M. J. Schmidt-Kessen, "Creating markets in no-trust environments: The law and economics of smart contracts," Computer Law \& Security Review: The International Journal of Technology Law and Practice, 2018, https:// doi.org/10.1016/j.clsr.2018.09.003, pp. 19-20.

${ }^{102}$ A. Somma, Introducción al Derecho Comparado, traducción de E. Conde Naranjo, Universidad Carlos III de Madrid, 2015, p. 167.

${ }^{103}$ R. Pardolesi Y M. Granier, "El Futuro de los Profesores de Derecho y el Derecho Comparado", Revista ius et veritas, vol. 49, diciembre 2014, pp. 16-39, p. 27. 
la elección de la ley más favorable o en su defecto, de la ley de la residencia habitual de la parte más débil. Y, para el resto de contratos, mediante el mecanismo de las normas imperativas de la lex causae y de las normas internacionalmente imperativas o leyes de policía en el sentido recogido por el art. 9(1) Reglamento de Roma I, que comprende tanto las normas internacionalmente imperativas del foro (art. 9(2)), como las del país de ejecución si hacen esta ilegal (art. 9(3)).

55. Sin embargo, cuando se trata de relaciones jurídicas sometidas a un alto grado de autorregulación que se desenvuelven exclusivamente en la red y que remiten a plataformas online para la resolución de controversias, la defensa de los intereses públicos y generales, es y será, más complicada. Aquí las decisiones se toman a través de mecanismos de enjuiciamiento "por pares" por árbitros, jueces o miembros de la cadena de bloques, que no son guardianes de ningún sistema jurídico estatal. La aplicación de Lex Cryptographia no encuentra en estos casos ningún control desde el punto de vista del Derecho estatal, ni siquiera a la hora de ejecutar la decisión, que se realiza directamente dentro de la cadena de bloques. ${ }^{104}$ Ante esta situación, dos son las posibles soluciones: a) desarrollar unas normas de conflicto especiales que regulen la relación entre la Lex Cryptographia y la legislación nacional ${ }^{105}$ y b) que el legislador mismo se involucre en el desarrollo de esta tecnología desde dentro. Esta última posibilidad parece la opción más acertada, ya que de esta manera puede controlar y regular la industria y estar mejor posicionado para aprovechar las oportunidades, a medida que vayan surgiendo. ${ }^{106}$ Creemos que, a la postre, será la mejor forma de salvaguardar el interés general, puesto que toda intervención legislativa externa corre el riesgo de caer en saco roto, a medida que se vaya incrementando el número de operaciones y situaciones con virtualidad exclusiva dentro de la red.

\section{Conclusiones}

56. "El código es ley" dictaminaba LaWRenCe Lessig en su obra Code 2.0, construyendo con sus palabras puentes entre dos mundos, el informático y el jurídico: "hoy, quien programa, potencialmente legisla”. ${ }^{107}$ El código es la letra de la ley y el algoritmo es la estructura que define el proceso.

57. Entre las visiones más radicales sobre informática y Derecho está aquella que aventura que la tecnología someterá al ordenamiento a las fuerzas del mercado y romperá el monopolio legislativo y judicial del Estado. Esta idea ha sido discutida por muchos autores, incluyendo RoBERT NOzicK, MurRaY RothBARD y DAVID FrIEDMAN, ${ }^{108}$ para los que el propósito del sistema jurídico es proteger la propiedad privada y hacer valer los derechos de los ciudadanos, incluida la autonomía de la voluntad. Si las nuevas tecnologías digitales avanzan hasta un punto en el que realmente no hay necesidad de garantizar estos derechos por terceros, el ordenamiento estatal será superfluo, así como sus costes asociados, considerados por muchos libertarios como injustificables. ${ }^{109}$

58. Siguiendo esta estela de pensamiento, algunos autores han proclamado la aparición de la denominada Lex Cryptographia, entendida como el conjunto de normas que operan a través de contratos

\footnotetext{
${ }^{104}$ U. R. Rodrigues, "Law and the Blockchain,” Iowa Law Review, vol. 104, 2019, pp. 679-729, p. 715.

${ }^{105}$ F. Möslein, "Legal Boundaries of Blockchain Technologies: Smart Contracts as Self-Help?”, en A. De Franceschi y R. Schulze (eds.), Digital Revolution - New x for Law, Munich, C. H. Beck, 2019, pp. 313-326, p. 316.

106 T. Lyons, L. COURCELAS y K. Timsit, Legal and regulatory framework of blockchains and smart contracts, https://www. eublockchainforum.eu/sites/default/files/reports/report_legal_v1.0.pdfInforme, p. 34 (consultado el 7 de diciembre de 2020); "La regulación de Blockchain y los Smart contracts va a requerir la armonización de conceptos, principios, regulación e interpretaciones", Especial Directivos, núm. 1765, 1 de noviembre de 2019, pp. 38-42, p. 40.

${ }^{107}$ L. Lessig, The Code version 2.0, Cambridge, Basic Books, 2006.

${ }^{108}$ R. Nozick, Anarchy, State, And Utopia, Nueva York, Basic Books, 1974; M. Rothвard, The Ethics of Liberty, New York University Press, 1982; D. Friedman, The Machinery Of Friedman, Chicago, Open Court Publishing Company, 1973 ; E. Stringham, Anarchy And The Law, New Brunswick, NJ, Transaction Publishers, 2007.

${ }^{109}$ M. RASKIn, “The Law and Legality of Smart Contracts”, Georgetown Law Technology Review, vol. 1, 2017, pp. 305-341, p. 335 .
} 
inteligentes autoejecutables y organizaciones autónomas descentralizadas, que está llamada a desplazar al Derecho estatal y a jueces y tribunales. ${ }^{110}$

59. A diferencia de los sistemas jurídicos tradicionales, cuyas disposiciones son universales y aplicables para todos, bajo este nuevo paradigma, los operadores son libres de elegir aquel conjunto particular de disposiciones disponibles en la red que mejor reflejen sus preferencias o necesidades. Ello puede desembocar en el caso más extremo en un gobierno algorítmico ${ }^{111}$ esto es, un nuevo sistema normativo capaz de regular la sociedad de manera más eficiente, que suprimiría los costes de la aplicación de la ley y que permitiría un sistema personalizado de reglas para cada ciudadano, revisables constantemente en función de sus preferencias y perfiles correspondientes. Una dictadura de los datos o Ciberleviatán, en palabras de LASSALle. ${ }^{112}$

60. Por otra parte, para estimular la innovación, el empleo y el crecimiento económico, desarrolladores, empresas y el ecosistema tecnológico en general dependen de un marco jurídico comprensible, predecible y adecuado que constituya la base de una industria digital próspera. Sin él, muchas startups no podrán llevar a cabo sus proyectos por miedo a futuras responsabilidades legales inciertas, las plataformas pueden tener dificultades para encontrar usuarios por la ausencia de una protección jurídica adecuada y, posiblemente, costará despertar el interés sobre los nuevos tipos de activos digitales. La incursión del legislador en el ámbito de la contratación inteligente es, por tanto, necesaria.

61. La profundidad del análisis jurídico necesario para llevar a cabo la regulación sustantiva de esta tecnología a nivel local o una armonización transfronteriza de manera efectiva, exige cautela. Además, dada la velocidad del desarrollo tecnológico y la expansión de sus aplicaciones, el legislador corre el riesgo de que la normativa que adopte quede desfasada, incluso antes de entrar en vigor.

62. En consecuencia, la autorregulación, en conexión con el Derecho internacional privado, están llamados a jugar un papel central a la hora de garantizar la seguridad jurídica y la defensa de los intereses públicos y generales, fomentando, al mismo tiempo, el desarrollo de las mejores soluciones a nivel legislativo e incentivando la innovación tecnológica. A tal efecto, se deberá promover la elección de la ley aplicable, tanto a nivel individual, como en los términos y condiciones que rigen para cada cadena de bloques. Asimismo, se aconseja la adopción de una norma de conflicto específica para las transacciones que se desarrollan en la cadena de bloques con carácter exclusivo. En ausencia de elección, la ley del país con los vínculos más estrechos proporciona un grado de flexibilidad adecuado para la mayoría de situaciones. No obstante, cuando la deslocalización de la transacción impide establecer razonablemente la ley del país con los vínculos más estrechos, la lex fori se presenta como la solución que aporta más seguridad jurídica y previsibilidad.

63. El Derecho internacional privado contiene, en consecuencia, elementos decisivos para obligar al legislador a promulgar normas eficaces, que reflejen un equilibrio adecuado entre innovación tecnológica y la protección de los intereses generales. En último término, además, la competencia regulatoria que posibilita la autonomía de la voluntad, puede desembocar en la armonización transfronteriza del marco regulatorio de la contratación inteligente.

64. La intervención legislativa deberá ir orientada, así, a garantizar el interés general en su grado justo. Pero las redes de la Lex Cryptographia son fuertes; mucho más que las de la Lex Mercatoria.

${ }^{110}$ A. Wright y P. DE FiLIPPI, "Decentralized Blockchain Technology and the Rise of Lex Cryptographia" (10 de marzo de 2015), p. 4. Disponible en SSRN: https://ssrn.com/abstract=2580664 (consultado el 7 de diciembre de 2020); F. GuILLAUME, "Aspects of private international law related to blockchain transactions", en D. KRAUS, T. OBRIST y O. HARI (eds), Blockchains, Smart Contracts, Decentralised Autonomous Organisations and the Law, Edward Elgar Publishing, 2019, pp. 49-82.

${ }^{111}$ A. Wright y P. De FilipPI, "Decentralized Blockchain Technology and the Rise of Lex Cryptographia" (10 de marzo de 2015), p. 41. Disponible en SSRN: https://ssrn.com/abstract=2580664 (consultado el 7 de diciembre de 2020).

112 J. M. Lassalle, Ciberleviatán, Barcelona, Arpa Editores, 2019. 
Mientras que esta última necesita del sistema judicial y está sometida a su escrutinio al no disponer de mecanismos coercitivos propios, la Lex Crytographia opera a través de mecanismos autoejecutables, que limitan al máximo el margen de intervención del aparato jurídico estatal. Como se ha señalado en el apartado II, ya hay ejemplos de entidades y situaciones que existen en la cadena de bloques de forma exclusiva y cabría pensar que, en la medida que la red se consolida y la tecnología avanza, el número de transacciones totalmente deslocalizadas no hará sino aumentar. Aquí, la protección de los intereses generales mediante la aplicación de las normas de policía no alcanza, sobre todo, si la resolución de controversias se somete a una "jurisdicción online". Por consiguiente, al legislador no le queda otra que involucrarse en el desarrollo de la red desde dentro. De esta forma, podrá velar por el interés público en primera línea de acción y estará bien posicionado para aprovechar las oportunidades que la red ofrece. 